\title{
Standardizing training for Pressurized Intraperitoneal Aerosol Chemotherapy
}

\author{
Mohammad Alyami ${ }^{\text {a, }}$, Olivia Sgarbura ${ }^{\text {b }}$, Vladimir Khomyakov ${ }^{c}$, Philipp Horvath ${ }^{\text {d }}$, \\ Giuseppe Vizzielli ${ }^{\mathrm{e}}$, Jimmy So ${ }^{\mathrm{f}}$, Juan Torrent ${ }^{\mathrm{g}}$, Xavier Delgadillo ${ }^{\mathrm{h}}$, David Martin ${ }^{\mathrm{i}}$, \\ Wim Ceelen ${ }^{\mathrm{j}}$, Marc Reymond ${ }^{\mathrm{d}}$, Marc Pocard ${ }^{\mathrm{k}, 1}$, Martin Hübner ${ }^{\mathrm{i}}$ \\ ${ }^{a}$ Department of General Surgery and Surgical Oncology, Oncology Center, King Khalid Hospital, Najran, Saudi Arabia \\ ${ }^{\mathrm{b}}$ Department of Surgical Oncology, Cancer Institute in Montpellier, France \\ c Moscow Research Oncological Institute n.a. P.A. Herzen, Thoracoabdominal, Moscow, Russian Federation \\ "University of Tuebingen, Germany \\ e Fondazione Policlinico Universitario "A. Gemelli" IRCCS, Roma, Italy \\ ${ }^{\mathrm{f}}$ National University Hospital, Singapore \\ g QTI Comprehensive Cancer Center, Barcelona, Spain \\ ${ }^{\text {h }}$ CMC Volta, La Chaux-de-Fonds, Switzerland \\ i Department of Visceral Surgery, Lausanne University Hospital CHUV, University of Lausanne (UNIL), Switzerland \\ ${ }^{\mathrm{j}}$ Ghent University, Belgium \\ ${ }^{\mathrm{k}}$ Université de Paris, UMR 1275 CAP Paris-Tech, F-75010, Paris, France \\ ${ }^{1}$ Service de Chirurgie Digestive et Cancérologie Hôpital Lariboisière, 2 rue Ambroise Paré, F-75010, Paris, France
}

\section{A R T I C L E I N F O}

\section{Article history:}

Received 4 January 2020

Received in revised form

28 April 2020

Accepted 8 May 2020

Available online 30 May 2020

\section{Keywords:}

PIPAC

Peritoneal cancer

Training course

Implementation

\begin{abstract}
A B S T R A C T
Background: PIPAC is a novel mode of intraperitoneal drug delivery for patients with peritoneal cancer (PC). PIPAC is a safe treatment with promising oncological results. Therefore, a structured training program is needed to maintain high standards and to guarantee safe implementation.

Methods: An international panel of PIPAC experts created by means of a consensus meeting a structured 2-day training course including essential theoretical content and practical exercises. For every module, learning objectives were defined and structured presentations were elaborated. This structured PIPAC training program was then tested in five courses.

Results: The panel consisted of 12 experts from 11 different centres totalling a cumulative experience of 23 PIPAC courses and 1880 PIPAC procedures. The final program was approved by all members of the panel and includes 12 theoretical units ( 45 min each) and 6 practical units including dry-lab and live surgeries. The panel finalized and approved 21 structured presentations including the latest evidence on PIPAC and covering all mandatory topics. These were organized in 8 modules with clear learning objectives to be tested by 12 multiple-choice questions. Lastly, a structured quantifiable (Likert scale $1-5$ ) course evaluation was created.

The new course was successfully tested in five courses with 85 participants. Mean overall satisfaction with the content was rated at $4.79( \pm 0.5)$ with at $4.71( \pm 0.5)$ and at $4.61( \pm 0.7)$, respectively for course length and the balance between theory and practice.

Conclusions: The proposed PIPAC training program contains essential theoretical background and practical training enabling the participants to safely implement PIPAC.
\end{abstract}

๑) 2020 Elsevier Ltd, BASO The Association for Cancer Surgery, and the European Society of Surgical Oncology. All rights reserved.
Abbreviations: PIPAC, Pressurized Intraperitoneal Aerosol Chemotherapy; PC, peritoneal cancer; QoL, quality of life; VAS, visual analogue scale.

* Corresponding author. Department of General Surgery \& Surgical Oncology, Oncology Center, King Khalid hospital Najran, King Abdulaziz Street, B.O.Box 1120, Najran, 66262, Saudi Arabia.

E-mail address: swar_ms@hotmail.com (M. Alyami).

\section{Introduction}

Pressurized Intraperitoneal Aerosol Chemotherapy (PIPAC) is a novel mode of intraperitoneal drug delivery for patients with peritoneal cancer (PC) [1,2]. After first use in-human in November 
2011, PIPAC was adopted first by a handful of academic centres in Europe creating a solid body of evidence (104 peer-review publications by January 31st' 2019) which was summarized in three recent systematic reviews(3-5). PIPAC treatment was shown to be feasible, safe and well-tolerated in patients with peritoneal cancer (PC) of different primaries. Furthermore, level IIB evidence suggested oncological efficacy with no negative impact on quality of life (QoL) [3-5]. Therefore, interest for PIPAC treatment is steadily growing and 23 implementation courses were held between 2014 and 2018 by 9 different centres training an overall of 448 participants from 39 different countries from all continents. Furthermore, important practical and safety aspects have been summarized comprehensively [1,6-8] Of note, access to the nebulizer (Capnopen ${ }^{\circledR}$, Capnomed, Albring 81, 78658 Zimmer ob. Rottweil, Germany) is granted only to certified centres in order to assure safe use and scientific assessment of this novel and potentially dangerous technique. Currently, the demand for PIPAC training exceeds the capacity of training centres.

Therefore, expert centres agreed to create a structured training program containing theoretical modules with pre-defined learning objectives and practical exercises including certification test and course evaluation. The resulting course should be easily reproducible and it was tested in five upcoming PIPAC courses.

\section{Methods}

\section{Methodology and composition of expert panel}

The new PIPAC training curriculum was elaborated during a 5day consensus meeting in January 2019. Representatives from active PIPAC training centres were invited to join the working group. Any controversies were discussed among the experts and resolved if needed by majority vote $(>70 \%)$. The study was performed in accordance with the precepts established by the Declaration of Helsinki.

\section{Creating a structured PIPAC training curriculum}

In a first step, essential knowledge, structure, and learning objectives were decided. Second, theoretical and practical modules were created to satisfy the learning objectives (both in plenary session). Third, sample presentations from previous courses were selected, updated and adapted to fit with the defined formal requirements (discussed at small working groups). Care was taken to guarantee coherence with regards to topic, module and learning objective. All presentations were then presented to the panel for final approval. Lastly, experts assembled multiple-choice questions for the mandatory certification quiz reflecting essential knowledge on PIPAC technology according to the learning modules.

\section{Testing the structured PIPAC training curriculum}

For course evaluation, experts opted for a 2-page questionnaire with 26 questions to be answered on a Likert scale from 1 (strongly disagree) to 5 (strongly agree). Questions concerned the 5 areas A course design (5 questions), B course objectives (11 questions), C general evaluation of speakers (5 questions), D logistics (3 questions), and $\mathrm{E}$ summary (2 questions). The course evaluation is provided as online appendix 1 . Areas A, B and E were considered for evaluation of the new curriculum. In accordance to previous studies, and for information purposes, agreement was obtained when a statement was agreed or strongly agreed (Likert scale $\geq 4$ ) by $\geq 70 \%$ of the experts $[9,10]$.

The resulting structured PIPAC training curriculum was then tested for feasibility in the next five consecutive PIPAC courses in three established training centres (Lausanne, Montpellier and Tubingen) and two new centres (Saudi Arabia, course held in Dubai and Moscow). In order to guarantee similar quality of the course in the preliminary experience with the new curriculum, at least two members of the presenting faculty had been involved in the design of the new curriculum. Satisfaction of participants was evaluated as outlined before and the faculty was asked to evaluate the new curriculum on a Likert scale answering 5 questions on course content, the standardized presentations, balance between theory and practice, room for discussion, and feasibility (online appendix 1).

\section{Statistical analysis}

Descriptive statistics were utilized to summarize course evaluations. Continuous variables (VAS) were reported as mean (standard deviation) or median (interquartile range), and categorical variables as frequency (\%). Student's t-test and Chi-square were used for comparison of continuous and categorical variables, respectively. All statistical tests were two-sided accepting a level of 0.05 to indicate statistical significance. Data was analyzed by use of the Statistical Software for the Social Sciences SPSS Advanced Statistics 22 (IBM Software Group, 200 W. Madison St., Chicago, IL; 60606 USA).

\section{Results}

The consensus group consisted of 12 experts from 11 different centres with a cumulative experience of 23 PIPAC courses for 448 participants from 39 different countries (Table 1). The clinical experience of the expert panel was reflected by a total number of 1880 performed PIPAC procedures. Members of the group (co) authored 46 (44,6\%) out of the 103 peer-reviewed publications on PIPAC published before the course.

\section{PIPAC training curriculum}

The formal structure is a 2-day course including 8 theoretical and 4 practical modules of 45 min each. The defined learning objectives contain essential aspects on PIPAC technology, technique, occupational safety, regulatory and ethical aspects, as well as for current evidence and potential indications (Table 2). Learning objectives were attributed to the practical and theoretical modules. Every theoretical module included 3 presentations. 21 mandatory individual topics were identified as the core content. Three additional spots were reserved for facultative lectures to give flexibility to the organizers and to respond to individual requirements of the participants. The complete course content is given in Table 2.

The final program was approved by all members of the panel and includes 12 theoretical units (45min each) and 6 practical units including dry-lab and live surgeries. The panel finalized and approved 21 structured presentations including the latest evidence on PIPAC and covering all mandatory topics. These were organized in 8 modules with clear learning objectives to be tested by 12 multiple-choice questions. For this purpose, available presentations of previous PIPAC courses were scrutinized by the expert panel and adapted to the new format. The final versions of the 21 approved core presentations consist of 340 slides.

\section{Validation for the new PIPAC training curriculum}

The new curriculum was then tested in five PIPAC training courses with 85 participants. Detailed evaluation of course design and objectives are given in Fig. 1. 80 participants (94.1\%) rated overall satisfaction with the course as very high $(n=68)$ or high $(\mathrm{n}=12)$ with no negative and 5 missing evaluations. Similarly, 80 participants would recommend (very strong: 72 , strong: 7,5 
Table 1

Previous PIPAC courses.

\begin{tabular}{|c|c|c|c|c|c|}
\hline Country & Center & Editions & Languages & Dates & Participants \\
\hline \multirow[t]{2}{*}{ Germany } & Herne & 4 & English & $\begin{array}{l}\text { October 2014, February 2015, May 2015, } \\
\text { June } 2015\end{array}$ & 57 \\
\hline & Tübingen & 3 & English & October 2016, October 2017, October 2018 & 68 \\
\hline \multirow[t]{5}{*}{ Switzerland } & Lausanne & 4 & English & February 2016 & 101 \\
\hline & & & & February 2017 & \\
\hline & & & & February 2018 & \\
\hline & & & & September 2018 & \\
\hline & & & & February 2019 & \\
\hline \multirow[t]{3}{*}{ Italy } & Turin & 2 & English & May 2016 & 31 \\
\hline & & & & May 2017 & \\
\hline & Rome & 1 & English & December 2018 & 21 \\
\hline \multirow[t]{4}{*}{ France } & Lyon & 2 & French, English & January 2018 & 32 \\
\hline & & & & January 2019 & \\
\hline & Paris & 1 & English & April 2018 & 18 \\
\hline & Montpellier & 1 & Spanish & October 2018 & 16 \\
\hline \multirow[t]{2}{*}{ Danemark } & Odense & 2 & English & June 2017 & 31 \\
\hline & & & & May 2018 & \\
\hline \multirow[t]{2}{*}{ Singapore } & Singapore & 2 & English & November2017 & 47 \\
\hline & & & & October 2018 & \\
\hline South Korea & Seoul & 1 & English & July 2018 & 26 \\
\hline Total & & 23 & & & 448 \\
\hline
\end{tabular}

Countries of origin (alphabetic order): 39.

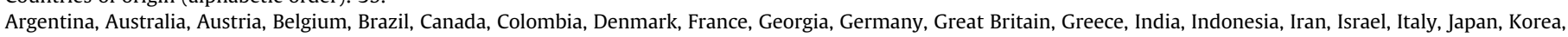

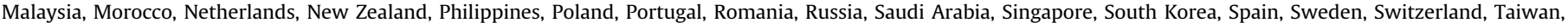
Turkey, United Emirates, USA.

Table 2

PIPAC training course content and Learning objectives of training curriculum.

\begin{tabular}{|c|c|c|}
\hline Module & Lectures & Learning objectives \\
\hline Module 1* & - Normal and diseased peritoneum & - Understand the rationale of this innovative drug delivery technology \\
\hline Why PIPAC ? & $\begin{array}{l}\text { - PIPAC Rationale } \\
\text { - Pathology lecture } \\
\text { - Radiology lecture }\end{array}$ & - Be able to assess therapy response after PIPAC \\
\hline Module 2* & - Ethical \& regulatory aspects & - Learn about ethical aspects and regulatory background \\
\hline PIPAC essentials & $\begin{array}{l}\text { - PIPAC technology } \\
\text { - Occupational health } \\
\text { - How to start a PIPAC program }\end{array}$ & - Master the occupational health safety aspects \\
\hline Module 3* (Pre)clinical data & $\begin{array}{l}\text { - Preclinical data } \\
\text { - Clinical evidence } \\
\text { - Toxicity, pitfalls and dangers }\end{array}$ & - Integrate the available evidence on PIPAC in treating peritoneal disease \\
\hline $\begin{array}{l}\text { Module } 4^{*} \\
\text { From theory to practice }\end{array}$ & - How I do it & - Familiarize with PIPAC technology and the operative technique \\
\hline $\begin{array}{l}\text { Module 5** } \\
\text { Hands-on training }\end{array}$ & - Dry lab & - Acquire PIPAC practical skills in dry lab \\
\hline Module 6** & - Live surgery 1 & - Enable participants to perform PIPAC by observing live surgery \\
\hline Module 6** & - Live surgery 2 & \\
\hline Module 7* & - Indications and contraindications & - Learn about potential indications of PIPAC \\
\hline Registry \& research & $\begin{array}{l}\text { - Registry } \\
\text { - Ongoing clinical trials } \\
\text { - Potential applications }\end{array}$ & - Consider research opportunities in gastrointestinal and gynecological oncology \\
\hline Module 8 & - MCQ & - Be able to start PIPAC program on your own institution \\
\hline Quality control & - Course evaluation & \\
\hline
\end{tabular}

* (Theoretical).

** (Practical).

missing) the course to other colleagues. Of note, there were no significant differences between the rating of participants trained in the expert or in the novice training centre, with the exception of items "technology" and "start" (Table 3).

The faculty's evaluation is displayed in Fig. 2 showing high acceptance of the curriculum among the experts with no difference between expert and novice centres.

\section{Discussion}

A structured curriculum for PIPAC training was elaborated consisting of 8 theoretical and 4 practical units covering all essential aspects for safe implementation and utilization of PIPAC in clinical practice. The presented program proved to be feasible, reproducible and well accepted passing its validation in five PIPAC training courses, 3 experts and 2 novice PIPAC training centres. The course content was approved and endorsed by International Society for Study of Pleura and Peritoneum (ISSPP).

PIPAC has been proposed as an alternative mode for intraperitoneal drug delivery in certain situations, claiming improved distribution, enhanced tissue uptake, better tolerance, and repeatability using minimally invasive $\operatorname{access}(1,2)$. The 1 st PIPAC was done by the German pioneer group on November 2011(11). Since that time, surgical techniques were standardized by the same 


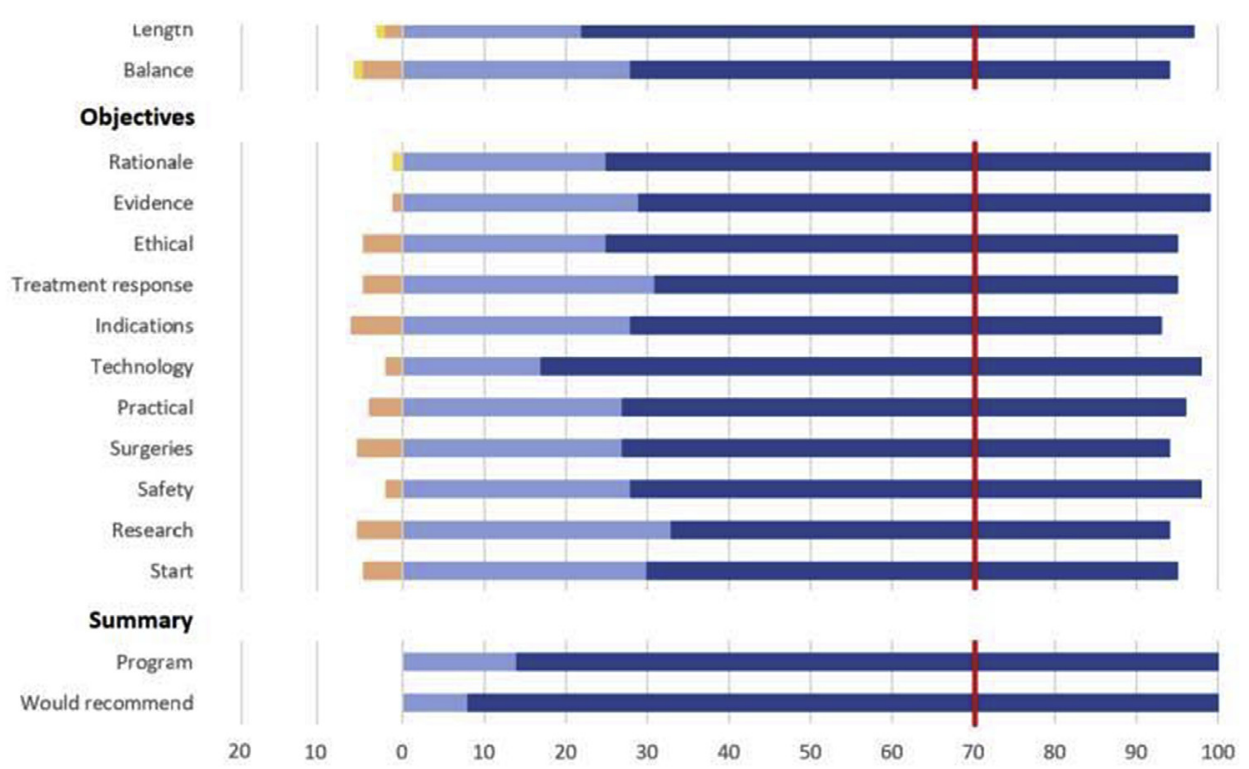

Fig. 1. PIPAC training curriculum evaluation by the participants

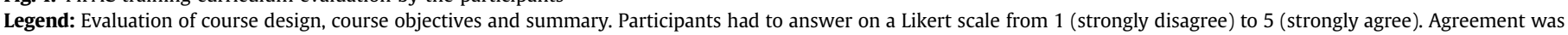
obtained when a statement was agreed or strongly agreed (Likert scale $\geq 4$ ) by $\geq 70 \%$ of the participants (red line).

Table 3

Comparison between expert and novice training centre (participants).

\begin{tabular}{|c|c|c|c|}
\hline & $\begin{array}{l}\text { Expert } \\
\text { Lausanne/Montpellier/Tübingen } n=57\end{array}$ & $\begin{array}{l}\text { Novice } \\
\text { Dubai/Moscow } n=28\end{array}$ & $P$-value \\
\hline \multicolumn{4}{|l|}{ Design } \\
\hline Program & $4.74(0.55)$ & $4.84(0.37)$ & 0.469 \\
\hline Length & $4.67(0.63)$ & $4.76(0.43)$ & 0.735 \\
\hline Balance & $4.54(0.68)$ & $4.68(0.55)$ & 0.417 \\
\hline \multicolumn{4}{|l|}{ Objectives } \\
\hline Rationale & $4.72(0.45)$ & $4.68(0.68)$ & 0.783 \\
\hline Evidence & $4.67(0.47)$ & $4.72(0.53)$ & 0.473 \\
\hline Ethical & $4.63(0.58)$ & $4.68(0.55)$ & 0.735 \\
\hline Treatment response & $4.59(0.56)$ & $4.56(0.64)$ & 0.986 \\
\hline Indications & $4.58(0.62)$ & $4.6(0.53)$ & 0.828 \\
\hline Technology & $4.70(0.53)$ & $4.96(0.20)$ & 0.019 \\
\hline Practical & $4.49(0.71)$ & $4.8(0.4)$ & 0.061 \\
\hline Surgeries & $4.57(0.62)$ & $4.68(0.55)$ & 0.473 \\
\hline Safety & $4.58(0.72)$ & $4.72(0.45)$ & 0.547 \\
\hline Research & $4.5(0.60)$ & $4.64(0.62)$ & 0.226 \\
\hline Start & $4.48(0.60)$ & $4.76(0.51)$ & 0.031 \\
\hline \multicolumn{4}{|l|}{ Summary } \\
\hline Program & $4.82(0.33)$ & $4.8(0.4)$ & 0.401 \\
\hline Would recommend & $4.90(0.29)$ & $4.92(0.27)$ & 0.874 \\
\hline
\end{tabular}

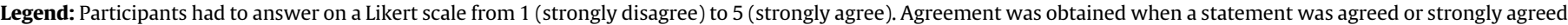
(Likert scale $\geq 4$ ) by $\geq 70 \%$ of the participants (red line). Results are presented as mean and standard deviation. Bold values indicate significant difference ( $\leq 0.05$ ).

group [2,11]. The intriguing concept and favourable initial reports triggered wide adoption of PIPAC, mainly in Europe [3-5]. The access to the nebulizer is granted only to certified centres in order to assure safe use and scientific assessment of this novel technique. Our study confirms that the new training course was applicable and highly rated by both, the participants and faculty members. A recent systematic review confirmed the homogeneity of technique, indications, and drug regimens among active centres(5) as suggested by an international multicentre survey with regards to current practice of PIPAC [12]. This is in contrast to the quite heterogeneous practice for others intra peritoneal drug delivery practice as Hyperthermic IntraPeritoneal Chemotherapy (HIPEC) procedures and can be explained by a standardized implementation process through dedicated training courses.
PIPAC practice is growing steadily with actually more than 5000 performed PIPAC procedures(5). The latest systematic review summarized the results of 1.810 published PIPAC procedures in 838 patients(5). This rapid and huge spread of PIPAC as a mode of drug delivery in the last 8 years was controlled by mandatory certification courses, which were initiated to assure the high level of safety and to maintain a homogenous use between centres [5,12]. Therefore, expert centres agreed to create a structured training program by ISSPP to maintain the high safety standards for spreading this novel treatment.

PIPAC courses for 2019 and 2020 will follow the new ISSPP training structure program. The current form of ISSPP training workshop was tested on 85 participants among them 80 (94.1\%) rated overall satisfaction and the same number of participants 


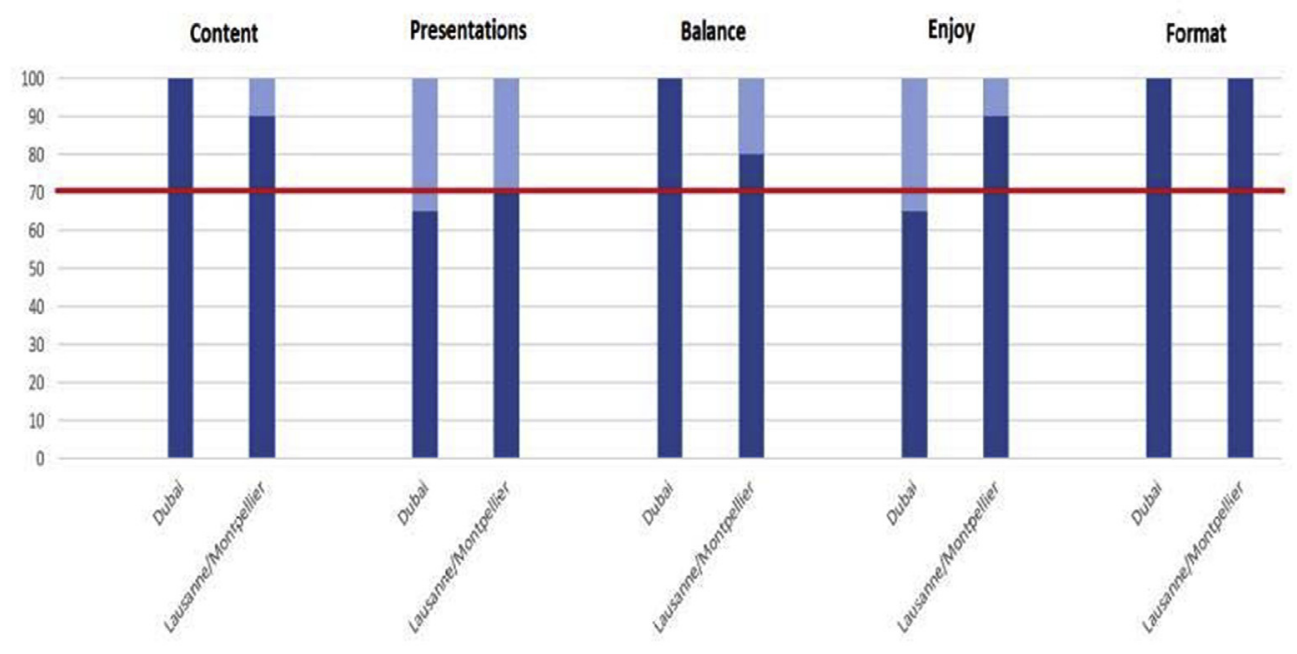

Likert scale 4 :

Fig. 2. Feasibility of the new PIPAC training curriculum assessed by faculty (expert vs novice)

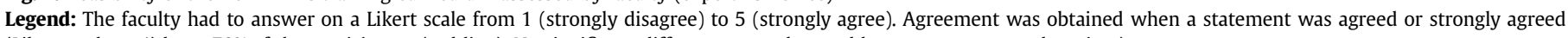
(Likert scale $\geq 4$ ) by $\geq 70 \%$ of the participants (red line). No significant difference was observed between experts and novices).

recommends the course to other colleagues. In addition, the faculty's evaluation showed high acceptance of the curriculum among the experts. Those data suggest a high standard curriculum, which will be revaluated and updated on 2020 by the ISSPP expert panel and will discuss the positive and the negative points to assure the same level of the scientific program. Furthermore, this standardized protocol will facilitate collection of homogenous data on PIPAC treatment for future studies on $\operatorname{PIPAC}(12)$.

A recent systemic review(5) confirmed that PIPAC has been broadly adopted and that introduction of this technology as a new mode of drug delivery has followed the IDEAL framework for surgical innovation [13]. Currently, PIPAC evaluation is proceeding to stage 3 (assessment) in several clinical trials for different indications (https://clinicaltrials.gov). Many studies in surgical oncology have shown that proper assessment of treatment needs proper data collection. The goal is to harmonize the treatment between centres, which is important especially when many active pharmacological substances are used [14]. For the management of PC by cytoreductive surgery (CRS) and HIPEC many study showed that there are a lack of consensus amongst CRS/HIPEC specialists with regards to patient selection and suitability with no high-level evidence-based guidelines on the issue [15-17]. In addition, several recent studies have called for standardization of CRS/HIPEC in terms of patient selection, HIPEC regimens (drugs, dosage, duration, temperature, mode), and perioperative care, as considerable variety exists among centres [18-20]. For this reason,it is very important to provide a structured training program for PIPAC to be followed by all centre worldwide to maintain homogeneity of practice(12). Mandatory certification and continuous evaluation of the courses will help to improve the standard of training in the future.

Several methodological limitations deserve mention. The proposed curriculum is no formal consensus among all PIPAC centres but the result of a rather small working group. This format appeared to be more useful to facilitate discussions and come to a result within a very short time frame (5 days). Credibility of the expert panel can be suggested by the fact, that the participants performed $100 \%$ of all PIPAC courses, more than 1880 PIPAC procedures and (co-)authored $44,6 \%$ of all publications on PIPAC. The current version of the PIPAC training curriculum has no pretention to be perfect. Updates and improvements are therefore foreseen once a year. Access to the technology could be considered as restricted by some, regarding the specific demand that certification is necessary. For that reason, adapted course training access had to be offered to every country and probably internet access and or massively open online courses MOOC'S had to be developed in the future.

\section{Conclusion}

A new PIPAC training curriculum has been elaborated and successfully validated in practice. Future courses shall therefore take advantage of these validated modules in order to maintain high standards, safe implementation of PIPAC in clinical practice. Furthermore, the resulting homogeneity regarding technique and indications could allow for multi-centre research projects.

\section{Declaration of competing interest}

The PIPAC course consensus meeting was supported by the International Society for the Study of Pleura and Peritoneum (ISSPP). Participants received no honorary or other personal sponsoring.

\section{CRediT authorship contribution statement}

Mohammad Alyami: Conceptualization, Methodology, Software, Validation, Formal analysis, Data curation, Writing - original draft, Writing - review \& editing, Supervision. Olivia Sgarbura: Conceptualization, Methodology, Software, Validation, Formal analysis, Data curation, Writing - original draft, Writing - review \& editing, Supervision. Vladimir Khomyakov: Conceptualization, Methodology, Software, Validation, Formal analysis, Data curation, Writing - original draft, Writing - review \& editing, Supervision. Philipp Horvath: Validation, Writing - review \& editing. Giuseppe Vizzielli: Validation, Writing - review \& editing. Jimmy So: Validation, Writing - review \& editing. Juan Torrent: Validation, Writing - review \& editing. Xavier Delgadillo: Validation, Writing review \& editing. David Martin: Validation, Writing - review \& 
editing. Wim Ceelen: Validation, Writing - review \& editing. Marc Reymond: Validation, Data curation, Writing - review \& editing. Marc Pocard: Validation, Writing - review \& editing. Martin Hübner: Conceptualization, Methodology, Software, Validation, Formal analysis, Data curation, Writing - original draft, Writing review \& editing, Supervision.

\section{Appendix A. Supplementary data}

Supplementary data to this article can be found online at https://doi.org/10.1016/j.ejso.2020.05.007.

\section{References}

[1] Solass W, Giger-Pabst U, Zieren J, Reymond MA. Pressurized intraperitonea aerosol chemotherapy (PIPAC): occupational health and safety aspects. Ann Surg Oncol 2013;20(11):3504-11.

[2] Solass W, Kerb R, Murdter T, Giger-Pabst U, Strumberg D, Tempfer C, et al Intraperitoneal chemotherapy of peritoneal carcinomatosis using pressurized aerosol as an alternative to liquid solution: first evidence for efficacy. Ann Surg Oncol 2014;21(2):553-9.

[3] Grass F, Vuagniaux A, Teixeira-Farinha $H$, Lehmann $K$, Demartines $N$ Hubner M. Systematic review of pressurized intraperitoneal aerosol chemotherapy for the treatment of advanced peritoneal carcinomatosis. Br J Surg 2017; 104(6):669-78.

[4] Tempfer C, Giger-Pabst U, Hilal Z, Dogan A, Rezniczek GA. Pressurized intraperitoneal aerosol chemotherapy (PIPAC) for peritoneal carcinomatosis: systematic review of clinical and experimental evidence with special emphasis on ovarian cancer. Arch Gynecol Obstet 2018:298(2):243-57.

[5] Alyami MHM, Grass F, Bakrin N, Villeneuve L, Laplace N, Passot G, et al Pressurised intraperitoneal aerosol chemotherapy: rationale, evidence, and potential indications. Lancet Oncol 2019;20(7):e368-77.

[6] Hubner M, Teixeira Farinha H, Grass F, Wolfer A, Mathevet P, Hahnloser D, et al. Feasibility and safety of pressurized intraperitoneal aerosol chemotherapy for peritoneal carcinomatosis: a retrospective cohort study. Gastroenterology research and practice 2017;2017:6852749.

[7] Giger-Pabst U, Tempfer CB. How to perform safe and technically optimized pressurized intraperitoneal aerosol chemotherapy (PIPAC): experience after a consecutive series of 1200 procedures. J Gastrointest Surg : official journal of the Society for Surgery of the Alimentary Tract 2018;22(12):2187-93.

[8] Cazauran JB, Alyami M, Lasseur A, Gybels I, Glehen O, Bakrin N. Pressurized intraperitoneal aerosol chemotherapy (PIPAC) procedure for non-resectable peritoneal carcinomatosis (with video). J Gastrointest Surg 2018 Feb;22(2): 374-5. https://doi.org/10.1007/s11605-017-3565-0. Epub 2017 Sep 12.

[9] Bonrath EM, Grantcharov TP. Contemporary management of paraesophaegeal hernias: establishing a European expert consensus. Surg Endosc 2015;29(8): 2180-95.

[10] Gero D, Gie O, Hubner M, Demartines N, Hahnloser D. Postoperative ileus: in search of an international consensus on definition, diagnosis, and treatment. Langenbeck's Arch Surg/Deutsche Gesellschaft fur Chirurgie 2017;402(1): 149-58.

[11] Solass W, Hetzel A, Nadiradze G, Sagynaliev E, Reymond MA. Description of a novel approach for intraperitoneal drug delivery and the related device. Surg Endosc 2012;26(7):1849-55.

[12] Nowacki M, Alyami M, Villeneuve L, Mercier F, Hubner M, Willaert W, et al. Multicenter comprehensive methodological and technical analysis of 832 pressurized intraperitoneal aerosol chemotherapy (PIPAC) interventions performed in 349 patients for peritoneal carcinomatosis treatment: an international survey study. Eur J Surg Oncol : the journal of the European Society of Surgical Oncology and the British Association of Surgical Oncology 2018:44(7):991-6.

[13] McCulloch P, Altman DG, Campbell WB, Flum DR, Glasziou P, Marshall JC, et al. No surgical innovation without evaluation: the IDEAL recommendations. Lancet 2009;374(9695):1105-12.

[14] Avigan MI, Bjornsson ES, Pasanen M, Cooper C, Andrade RJ, Watkins PB, et al. Liver safety assessment: required data elements and best practices for data collection and standardization in clinical trials. Drug Saf 2014;37(Suppl 1): S19-31.

[15] Spiegle G, Schmocker S, Huang H, Victor JC, Law C, McCart JA, et al. Physicians' awareness of cytoreductive surgery and hyperthermic intraperitoneal chemotherapy for colorectal cancer carcinomatosis. Canadian journal of surgery Journal canadien de chirurgie 2013;56(4):237-42.

[16] Yoo HJ, Hong JJ, Ko YB, Lee M, Kim Y, Han HY, et al. Current practices of cytoreductive surgery and hyperthermic intraperitoneal chemotherapy in the treatment of peritoneal surface malignancies: an international survey of oncologic surgeons. World J Surg Oncol 2018;16(1):92.

[17] Dube P, Sideris L, Law C, Mack L, Haase E, Giacomantonio C, et al. Guidelines on the use of cytoreductive surgery and hyperthermic intraperitoneal chemotherapy in patients with peritoneal surface malignancy arising from colorectal or appendiceal neoplasms. Curr Oncol 2015;22(2):e100-12.

[18] Turaga K, Levine E, Barone R, Sticca R, Petrelli N, Lambert L, et al. Consensus guidelines from the American Society of Peritoneal Surface Malignancies on standardizing the delivery of hyperthermic intraperitoneal chemotherapy (HIPEC) in colorectal cancer patients in the United States. Ann Surg Oncol 2014;21(5):1501-5.

[19] Maciver AH, Al-Sukhni E, Esquivel J, Skitzki JJ, Kane 3rd JM, Francescutti VA. Current delivery of hyperthermic intraperitoneal chemotherapy with cytoreductive surgery (CS/HIPEC) and perioperative practices: an international survey of high-volume surgeons. Ann Surg Oncol 2017;24(4):923-30.

[20] Shannon NB, Tan GHC, Chia CS, Soo KC, Teo MCC. Biphasic learning curve of cytoreductive surgery and hyperthermic intraperitoneal chemotherapy: technical competence and refinement of patient selection. Pleura Peritoneum 2018;3(4):20180122. 